\title{
Popular Article
}

\section{Rainwater Harvesting:An Eco-Friendly Technique of Conserve the Water}

\author{
Shishu Pal Singh ${ }^{1}$, Mahendra Pratap Gautam ${ }^{2}$, Narendra Kumawat ${ }^{3}$, Shivraj Singh ${ }^{4}$ \\ ${ }^{1}$ Agriculture Department, Collecrty Farm, Varanasi, Uttar Pradesh, India \\ ${ }^{2}$ Chaudharycharan Singh Universities, Meerut, Uttar Pradesh, India \\ ${ }^{3}$ Rajmata Vijayaraje Scindia Krishi Vishwa Vidyalaya, Gwalior, Madhya Pradesh, India \\ ${ }^{4}$ Globus Environmental Engineering Services, Lucknow, Utter Pradesh, India
}

\section{INTRODUCTION}

Rainwater harvesting is enjoying a renaissance of sorts in the world, but it traces its history to biblical times. Rainwater harvesting is the accumulation and storage of rainwater for reuse on-site, rather than allowing it to run off. Rainwater can be collected from rivers or roofs, and in many places, the water collected is redirected to a deep pit a reservoir with percolation. Its uses include water for gardens, livestock, irrigation, domestic use with proper treatment, indoor heating for houses, etc. The harvested water can also be used as drinking water, longer-term storage, and for other purposes such as groundwater recharge.

\section{What is Rain Water Harvesting?}

Rainwater harvesting is one of the simplest and oldest methods of self-supply of water for households. Rainwater harvesting is the collection and storage of rainwater for reuse on-site, rather than allowing it to run off. These stored waters are used for various purposes such as gardening, irrigation etc. The water can be collected from various surfaces and platforms and stored for later use. In most cases, the water is usually collected from rooftops and other hard surfaces (fig.1).

"Rain water harvesting is collection and storage of rain water that runs off from roof tops, parks, roads, open grounds, etc. This water runoff can be either stored or recharged into the ground water. Rain water harvesting is a technique of collection and storage of rain water in surface (storage tanks) or sub surface aquifer before it is lost as surface runoff.

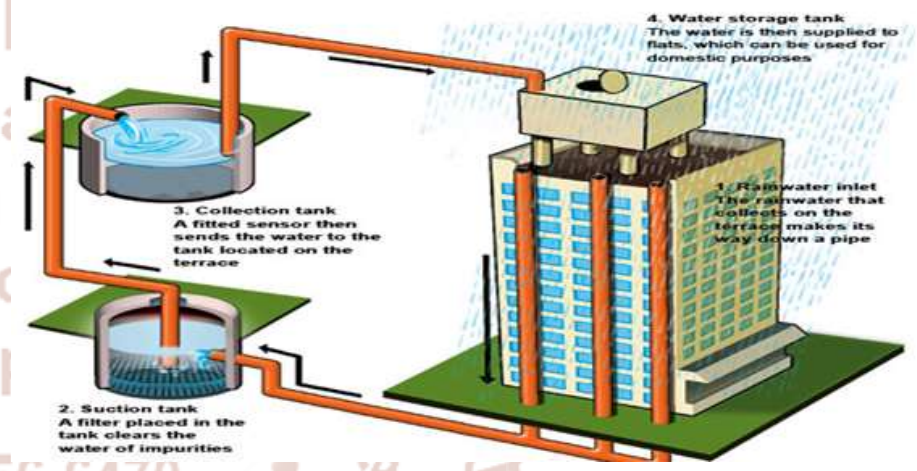

Fig. 1 Rainwater Harvesting System

Why Adopt Rain Water Harvesting System?

Today, scarcity of good quality water has become a major cause of concern. However rain water which is pure and of good quality is lost as run off Mains water is a precious resource due to increases in demand from our ever growing population. Rainwater harvesting can provide around 50 per cent of a family's water needs. This not only saves water, but saves money and reduces our impact on the environment. Reduces the runoff volume and the peak flow, hence mitigate floods. Recharges ground water thus is a solution to water shortage problem in winters. Reduces the cost per litre of water since a large amount of power that is consumed while pumping water from subsurface aquifers can be saved. There are nine basic reason of a Rain Water Harvesting system includes: 


\section{Conserves Water:}

Rainwater harvesting provides an alternative water source to well water and public water supplies. About 50 to $70 \%$ of all household water is used for landscape irrigation and other outdoor activities.

\section{Conserves Energy:}

Because rainwater harvesting bypasses the centralized water system, it conserves energy. Many household systems require only a small pump to create water pressure in the pipes, and many non-potable systems operate by gravity.

\section{Prevents Flooding And Erosion:}

Part of the local rainfall is diverted into collection tanks or passive harvesting methods, leaving less storm water to manage. Storm water problems are turned into water supply assets by slowing runoff and allowing it to soak into the ground.

\section{Decreases Water Contamination:}

Captured rainwater does not cause immediate runoff. Limiting runoff helps decrease the contamination of surface water by sediments, fertilizers, and pesticides in rainfall runoff.

\section{Reduces Personal Water Bills:}

Rainwater can be used in landscaping, for toilets, and for washing laundry. With more filtration and treatment, it can be used for cooking and drinking as well.

\section{Supplies Nutrients to Plants:}

Rainwater often contains nitrogen which provides a slight fertilizing effect for plants.

\section{Provides Naturally Soft Water:}

The use of rainwater can significantly reduce the amounts of detergents and soaps needed. It also prevents soap scum, hardness deposits, and the need for water softeners.

\section{Rainwater May Be Utilized For...}

1. Drinking, cooking, bathing (potable quality)

2. Toilet flushing

3. Washing clothes

4. Irrigation

5. Livestock requirements

\section{How Rainwater Harvesting Solves Water} Shortage?

Harvesting and collection of rainwater is a proper way that can be used to address the problem of the water crisis in various parts of the world. This simple water conservation method can be used to put forward a remarkable solution in areas where there is enough rainfall but not enough supply of groundwater. Bangalore is an excellent example where rainwater harvesting can become very beneficial. Bangalore is an area with a very high population and an area that also has to deal with water shortages. With these in mind, practicing water conservation methods such as rainwater harvesting is an ideal way to ensure increased supply of water. Bangalore experiences quite an immense amount of rainfall almost throughout the year. Hence, rainwater harvesting will play a huge role in providing additional sources of water. During the dry season, people will be able to have water sources if they have implemented the necessary kind of harvesting techniques. With increased demand for water, rainwater collection can be able to meet the requirements. When builders and architects are designing a new home or building, it is important that they think of implementing rainwater harvesting methods. It will be able to reduce reliability on other natural resources for groundwater. In the long run, there will be energy savings, water savings, and resource savings.

Where is The Build Rain Water System?

Water harvesting start is built as Individual homes, Colonies, Apartments, Institutions, Schools/colleges/universities, Clubs, Hospitals, Industries, Lums; Everywhere......the potential for rainwater harvesting is huge

\section{How to Harvest the Rain water}

Any rainwater harvesting system has three components: Catchment, Conveyance, and Storage. There are two classes of rainwater harvesting systems is (i) Systems which collect roof runoff for household use (ii) Systems which use in field or adjoining catchment to provide supplemental irrigation for agriculture.

\section{Components of a Rain Water Harvesting}

Rainwater harvesting system components are used for transporting rainwater through pipes or drains, filtration and tanks for storage of harvested water. There are six basic components of a Rain Water Harvesting system include:

\section{Catchments}

The surface which directly receives the rainfall and provides water to the system is called catchment area. 
It can be a paved area like a terrace or courtyard of a building, or an unpaved area like a lawn or open ground. A roof made of reinforced cement concrete. Coarse Mesh

It prevents the passage of debris, provided in the roof.

\section{Gutters}

Channels which surrounds edge of a sloping roof to collect and transport rainwater to the storage tank. Gutters can be semi - circular or rectangular and mostly made locally from plain galvanized iron sheet. Gutters need to be supported so they do not sag or fall off when loaded with water. The way in which gutters are fixed mainly depends on the construction of the house, mostly iron or timber brackets are fixed into the walls.

\section{Conduits}

Conduits are pipelines or drains that carry rainwater from the catchment or roof top area to the harvesting system. Commonly available conduits are made up of material like polyvinyl chloride (PVC) or galvanized iron (GI).

\section{First-flushing}

A first flush device is a valve which ensures flushing out of first spell of rain away from the storage tank that carries a relatively larger amount of pollutants from the air and catchment surface.

\section{Filters}

The filter is used to remove suspended pollutants from rainwater collected from roof top water. The Various types of filters generally used for commercial purpose are Charcoal water filter, Sand filters, Horizontal roughing filter and slow sand filter.

\section{Methods of Rainwater Harvesting}

\section{Surface runoff harvesting}

In urban area rainwater flows away as surface runoff. This runoff could be caught and used for recharging aquifers by adopting appropriate methods.

\section{Rooftop rainwater harvesting}

It is a system of catching rainwater where it falls. In rooftop harvesting, the roof becomes the catchments, and the rainwater is collected from the roof of the house/building. It can either be stored in a tank or diverted to artificial recharge system. This method is less expensive and very effective and if implemented properly helps in augmenting the groundwater level of the area.

\section{Advantages of Rainwater Harvesting}

\section{Easy to Maintain:}

Utilizing the rainwater harvesting system provides certain advantages to the community. First of all, harvesting rainwater allows us to better utilize an energy resource. It is important to do so since drinking water is not easily renewable and it helps in reducing wastage. Systems for the collection of rainwater are based on simple technology.

The overall cost of their installation and operation is much lesser than that of water purifying or pumping systems. Maintenance requires little time and energy. The result is the collection of water that can be used in substantial ways even without purification.

\section{Reducing Water Bills:}

Water collected in the rainwater harvesting system can be put to use for several non-drinking functions as well. For many families and small businesses, this leads to a large reduction in their utilities bill. On an industrial scale, harvesting rainwater can provide the needed amounts of water for many operations to take place smoothly without having to deplete the nearby water sources.

It also lessens the burden of soil erosion in a number of areas, allowing the land to thrive once again. In fact, it can also be stored in cisterns for use during times when water supplies are at an all-time low.

\section{Suitable for Irrigation:}

As such, there is little requirement for building new infrastructure for the rainwater harvesting system. Most rooftops act as a workable catchment area, which can be linked to the harvesting system. This also lessens the impact on the environment by reducing use of fuel based machines.

Rainwater is free from many chemicals found in ground water, making it suitable for irrigation and watering gardens. In fact, storing large reservoirs of harvested water is a great idea for areas where forest fires and bush fires are common during summer months.

\section{Reduces Demand on Ground Water:}

With increase in population, the demand for water is also continuously increasing. The end result is that many residential colonies and industries are extracting ground water to fulfill their daily demands. This has led to depletion of ground water which has gone to 
significant low level in some areas where there is huge water scarcity.

\section{Reduces Floods and Soil Erosion:}

During rainy season, rainwater is collected in large storage a tank which also helps in reducing floods in some low lying areas. Apart from this, it also helps in reducing soil erosion and contamination of surface water with pesticides and fertilizers from rainwater run-off which results in cleaner lakes and ponds.

\section{Can be used for Several Non-drinking Purposes:}

Rainwater when collected can be used for several non-drinking functions including flushing toilets, washing clothes, watering the garden, washing cars etc. It is unnecessary to use pure drinking water if all we need to use it for some other purpose rather than drinking.

\section{Disadvantages of Rainwater Harvesting}

\section{Unpredictable Rainfall:}

Rainfall is hard to predict and sometimes little or no rainfall can limit the supply of rainwater. It is not advisable to depend on rainwater alone for all your water needs in areas where there is limited rainfall. Rainwater harvesting is suitable in those areas that receive plenty of rainfall.

\section{Initial High Cost:}

Depending on the system's size and technology level, a rainwater harvesting system may cost anywhere between $\$ 200$ to $\$ 2000$ and benefit from it cannot be derived until it is ready for use. Like solar panels, the cost can be recovered in 10-15 years which again depends on the amount of rainfall and sophistication of the system.

\section{Regular Maintenance:}

Rainwater harvesting systems require regular maintenance as they may get prone to rodents, mosquitoes, algae growth, insects and lizards. They can become as breeding grounds for many animals if they are not properly maintained.

\section{Certain Roof Types may Seep Chemicals or Animal Droppings:}

Certain types of roofs may seep chemicals, insects, dirt or animals droppings that can harm plants if it is used for watering the plants.

\section{Storage Limits:}

The collection and storage facilities may also impose some kind of restrictions as to how much rainwater you can use. During the heavy downpour, the collection systems may not be able to hold all rainwater which ends in going to drains and rivers.

\section{References}

1. Sarma A.K., Giraud G., Baishya M.D., Rainwater Harvesting for Urban Flood Peak Reduction, My Green Earth-a Journal of Society for Socio Economic Awareness and Environment Protection, SSEAEP, Dec 2006, Vol. 3, No. 2, pp $14-21$

2. Sarma A.K. and Goswami P., Developing Intensity Duration Curve with Limited Rainfall Data, In the Book Predictions in Ungauged Basins for Sustainable Water Resource Planning and Management, Jain Brothers, New Delhi, November 2006, pp. 187-194, ISBN: 81-8360044-1 